\title{
QUANTITATIVE ANALYSIS OF CHOLESTEROL IN FOODS BY GAS-LIQUID CHROMATOGRAPHY
}

\author{
Takashi KanedA, Atsuko NakAjima, Kenshiro Fujimoto, ${ }^{1}$ \\ Tadashi KobAYASHI, ${ }^{2}$ Shuhachi KIRIYAMA, Kiyoshi EBIHARA, ${ }^{3}$ \\ Toshi InNAMI, Keisuke TsuJI, Etsuko TsUJI, ${ }^{4}$ \\ Toyosuke KINUMAKI, ${ }^{5}$ Hisako SHIMMA, ${ }^{6}$ \\ and Satoshi YONEYAMA ${ }^{7}$ \\ ${ }^{1}$ Laboratory of Food Science, Department of Food Chemistry, Faculty of Agriculture, \\ Tohoku University, 1-1 Amamiyamachi-Tsutsumidori, Sendai 980, Japan \\ ${ }^{2}$ Kobe Women's College of Pharmacy, 4-19-1 Motoyama- \\ kitamachi, Higashinada-ku, Kobe 658, Japan \\ ${ }^{3}$ Department of Agricultural Chemistry, Faculty of Agriculture, \\ Ehime University, 3-5-7 Tarumi, Matsuyama 790, Japan \\ ${ }^{4}$ National Institute of Nutrition, 1 Toyama-cho, Shinjuku-ku, Tokyo 162, Japan \\ ${ }^{5}$ Tokai Regional Fisheries Research Laboratory, 5-5-1 Kachidoki, \\ Chuo-ku, Tokyo 104, Japan \\ ${ }^{6}$ National Research Institute of Aquaculture, Tamaki-cho, \\ Watarai-gun, Mie 519-04, Japan \\ ${ }^{7}$ Japan Food Research Laboratories, 52-1 Motoyoyogi-cho, \\ Shibuya-ku, Tokyo 151, Japan
}

(Received June 17, 1980)

Summary In order to develop a simple and exact analytical method for cholesterol determination in foods by gas-liquid chromatography, several experiments were carried out in collaboration with several universities and institutes. For the extraction of lipids from foods, it was decided that chloroform-methanol $(2: 1)$ extraction was the most suitable procedure. Since pretreatment procedures using methods such as thinlayer chromatography and florisil column chromatography to purify the unsaponifiable matters reduced the recovery of cholesterol, and good results were obtained without applying the pretreatment, these procedures were concluded to be unnecessary. Gas chromatograms obtained with free sterol showed results similar to those of the trimethylsilyl ether derivative and acetate. $5-\alpha$-Cholestane is used as a good internal standard.

Keywords cholesterol, cholesterol determination, food analysis, extraction of unsaponifiable matters, gas-liquid chromatography

1 金田尚志, 中島敦子, 藤本健四郎, ${ }^{2}$ 小林 正, ${ }^{3}$ 桐山修八, 海老原 清, ${ }^{4}$ 印南 敏, 辻 啓介, 辻 悦子, ${ }^{5}$ 衣巻豊輔, ${ }^{6}$ 新間脩子, ${ }^{7}$ 米山 智 
The Japanese Resources Bureau, Science and Technology Agency, is planning to reform the standard tables of food composition in Japan, and in this program it was decided to add the cholesterol contents of several foods to the tables. We were requested to develop a simple and exact analytical method for cholesterol determination in foods.

The determination of cholesterol is usually carried out by colorimetric methods $(1,2)$, but these methods are unsuitable for cholesterol in foods because of the presence of a considerable amount of several interfering sterols in some foods such as shell-fish $(3,4)$. Therefore, we decided to study the determination of cholesterol by gas-liquid chromatography(GLC) which had been known to be suitable for sterol separation (5). This study was carried out in collaboration with several universities and national institutes.

\section{EXPERIMENTAL}

Reagents. Cholesterol and 5- $\alpha$-cholestane were purchased from Nakarai Chemicals Ltd., Kyoto, and used without further purification. Analytical grade reagents and solvents were used throughout this work.

Materials. Foofstuffs for cholesterol estimation were obtained on the market. Lipids of egg yolk, Kotama-gai (a type of clam, Gomphia melanaegis), Euphausia sp., and oyster (Crassostrea gigas) were extracted with chloroform-methanol (2:1). Oyster sterols were separated from the unsaponifiable lipid matter by crystallization from methanol. Lard fatty acid methyl ester was prepared from the mixture of fatty acids after removal of unsaponifiables.

Procedure for the determination of cholesterol. The procedure proposed for the GLC determination of cholesterol in foods is summarized in Fig. 1. A sample of food is accurately weighed. If it is a dry sample, it should be homogenized with the addition of rather large amounts of water. After adding an aliquot of 5- $\alpha$ cholestane chloroform solution (internal standard solution), lipids are extracted with a mixture of chloroform and methanol $(2: 1)$. The lipids are saponified and then the unsaponifiable matter is extracted with diethyl ether. After drying the solution over anhydrous sodium sulfate, the solvent is evaporated under reduced pressure. The resulting residue is dissolved in a small amount of diethyl ether and then applied to GLC under the conditions described in Table 1.

Figure 2 shows the calibration curve of cholesterol. A linear correlation between the weight ratios and peak ratios of cholesterol to 5- $\alpha$-cholestane as an internal standard was observed. The amount of cholesterol in foods can be calculated by the formula described in Table 2 . The conversion factor $(K)$ in the formula can be obtained from a calibration curve. The factor of 1.253 shown in Fig. 2 is an example of the conversion factor obtained in the Tohoku Univ. Lab. 


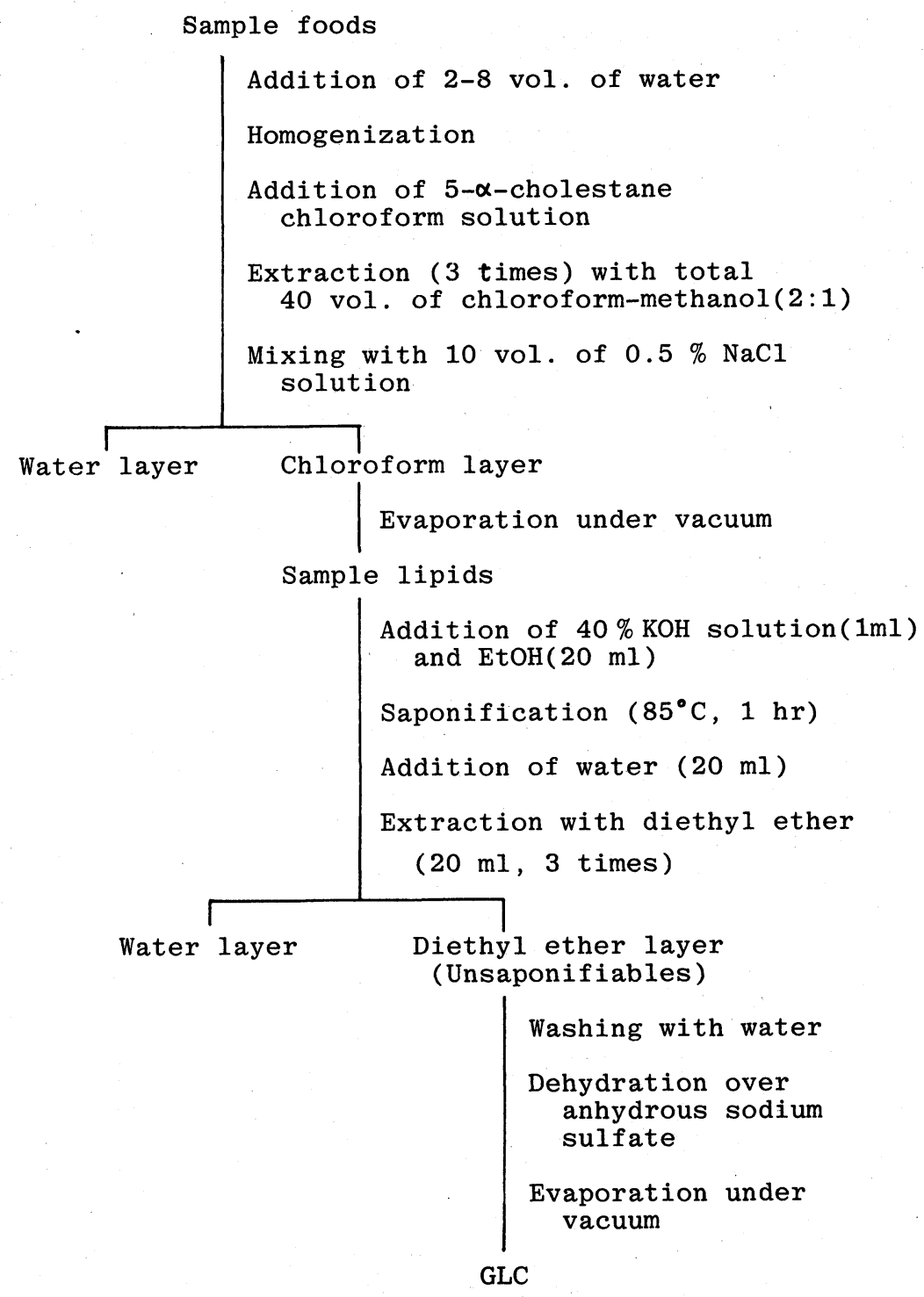

Fig. 1. Cholesterol determination procedure in foods.

\section{RESULTS AND DISCUSSION}

Experiment 1. Investigation on extraction methods of lipids from foods

For the determination of cholesterol in foods it is necessary to extract the lipids from foods and then to obtain the unsaponifiable matter. Comparison of the yields of the lipids from foods was carried out by using several solvents. Chloroform-methanol, hot benzene, acetone and diethyl ether were used as the 
Table 1. Conditions of GLC for the determination of cholesterol in Tohoku Univ. Lab.

Apparatus

Detector

Column condition

Column temp.

Injection temp.

Detector temp.

Carrier gas pres.

Hydrogen gas pres.

Air pres.
JEOL 20 KFP (Jpn. Elec. Co., Ltd.)

Hydrogen flame ionization detector

$3 \mathrm{~mm} \times 100 \mathrm{~cm}$ glass spiral tube packed with $5 \%$ SE-30 on Chromosorb W-AW, DMCS (80-100 mesh)

$260^{\circ} \mathrm{C}$

$290^{\circ} \mathrm{C}$

$300^{\circ} \mathrm{C}$

$0.8 \mathrm{~kg} / \mathrm{cm}^{2}\left(\mathrm{~N}_{2}\right)$

$0.7 \mathrm{~kg} / \mathrm{cm}^{2}$

$1.0 \mathrm{~kg} / \mathrm{cm}^{2}$

Table 2. Formula for the calculation of cholesterol content.

Amount of cholesterol in food $(\mathrm{mg} / 100 \mathrm{~g})$

$P_{\mathrm{sa}}:$ Peak area of cholesterol

$$
=\frac{P_{\mathrm{sa}} \times K}{P_{\mathrm{st}}} \times \frac{S_{\mathrm{t}}}{W} \times 100
$$

$P_{\text {st: }}$ : Peak area of internal standard (5- $\alpha$-cholestane)

$K$ : Conversion factor obtained from calibration curve

$S_{\mathrm{t}}$ : Weight of internal standard $(\mathrm{mg})$

$W$ : Weight of sample (g)

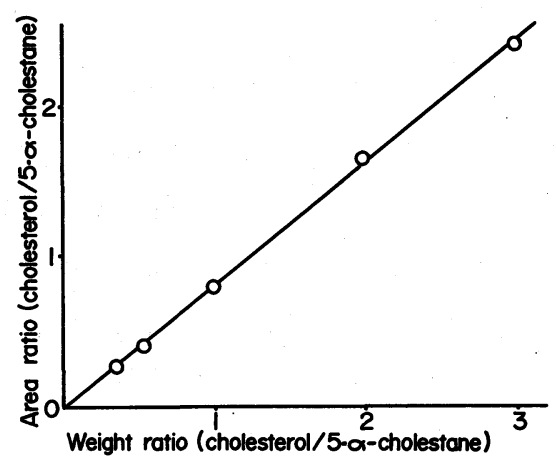

Fig. 2. Calibration curve of cholesterol. Coversion factor: $K=1 / 0.798=1.253$.

solvents. Short-necked clam (Tapes philippinarum) and top-shell (Batillus cornutus) were chosen as samples, because such shell-fish are known to contain several kinds of sterols $(3,4)$.

Table 3 shows that a mixture of chloroform and methanol in the ratio of $2: 1$ $(\mathrm{v} / \mathrm{v})$ is the most suitable solvent system to extract the lipids more exhaustively from foods. The lipids extracted from foods by each solvent system were saponified in ethanolic alkali solution and the unsaponifiable matter was extractd with diethyl 
Table 3. Comparison of solvents for the extraction efficiency of lipids and cholesterol in foods.

\begin{tabular}{llccc}
\hline \multirow{2}{*}{ Food } & \multicolumn{1}{c}{ Solvent } & $\begin{array}{c}\text { Lipids } \\
(\%)\end{array}$ & $\begin{array}{c}\text { Yield } \\
\text { Unsap. m. } \\
(\mathrm{mg} / 100 \mathrm{~g})\end{array}$ & $\begin{array}{c}\text { Cholesterol } \\
(\mathrm{mg} / \mathrm{100})\end{array}$ \\
\hline \multirow{3}{*}{$\begin{array}{l}\text { Short-necked } \\
\text { clam }\end{array}$} & Chloroform-methanol $(2: 1)$ & 1.55 & 215 & 42.8 \\
& Hot benzene & 1.20 & 187 & 35.8 \\
& Acetone & 0.67 & 153 & 32.6 \\
& Diethyl ether & 0.96 & 191 & 33.7 \\
\hline \multirow{3}{*}{ Top-shell } & Chloroform-methanol $(2: 1)$ & 0.97 & 195 & 150.9 \\
& Hot benzene & 0.73 & 168 & 128.2 \\
& Acetone & 0.37 & 159 & 104.1 \\
& Diethyl ether & 0.37 & 194 & 139.6 \\
\hline
\end{tabular}

ether. Cholesterol was estimated by applying the unsaponifiable matter to GLC. Since the results indicated that the assayed values of cholesterol were the highest when the chloroform-methanol extraction procedure was applied to both the samples of short-necked clam and top-shell (Table 3), the extraction procedure using the chloroform-methanol system was employed in subsequent experiments.

\section{Experiment 2. Investigation on the effect of pretreatment}

Several procedures such as thin-layer chromatography (TLC)(6), florisil column chromatography(7), and the precipitation with digitonin $(8)$ have been reported to remove impurities from the unsaponifiable matter in the determination of cholesterol. Therefore, the effects of pretreatment procedures on the assayed values of cholesterol in foods were compared. The three methods mentioned above as pretreatment procedures were investigated. First, synthesized triolein containing $70.7 \mathrm{mg}$ of cholesterol per $100 \mathrm{~g}$ oil was used as a sample for the collaborative test. When the recovery of cholesterol was examined by applying the method without any pretreatment, four laboratories gave a satisfactory result within 92 to $103 \%$ (Table 4), while that obtained from one laboratory (E) was $84 \%$, which might be an exception. On the other hand, when florisil column chromatography was used as a pretreatment procedure, the recoveries were very low except for that from one laboratory (B). Reduced recoveries were obtained also by Lab. (A) with TLC and precipitation with digitonin as pretreatment procedures.

In the next experiment, oyster sterols were used as another sample for collaborative testing, because the lipids are known to contain several sterols as impurities (3). A sample for the collaborative test was made by mixing $5.983 \mathrm{mg}$ of the oyster sterols with soybean oil. When the cholesterol content was determined, deviation among the laboratories was smaller than that obtained from the above experiment (Table 4).

Vol. 26, No. 5, 1980 


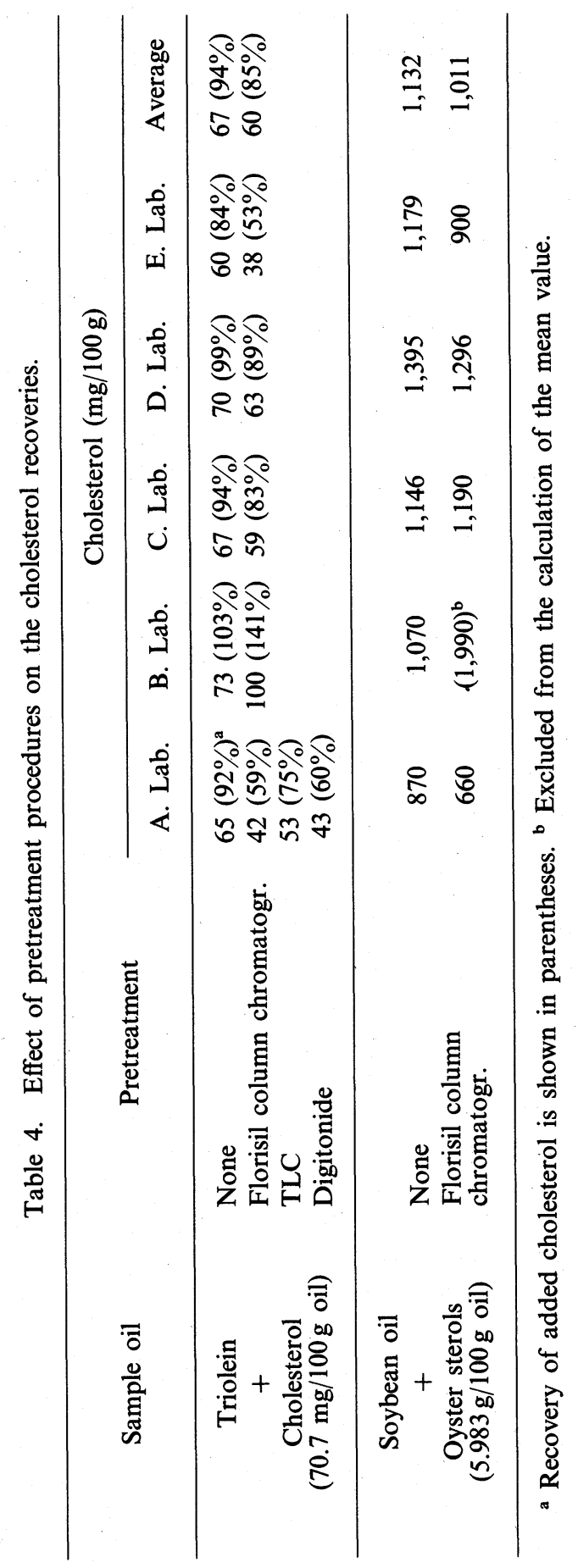


In order to see the pretreatments of the TLC and the digitonin precipitation, egg yolk lipids and oyster lipids were used which were similarly prepared by chloroform-methanol extraction. As shown in Table 5, the recoveries of cholesterol from yolk lipids tend to decrease with the application of TLC or the digitonin precipitation method. On the other hand, the results from the oyster lipids showed that reduced values by applying the TLC pretreatment were not clearly observed, whereas the digitonin precipitation method resulted in slightly decreased values.

In other experiments, sometimes it was noticed that these pretreatments yielded low recoveries of cholesterol. From these results, it was concluded that the pretreatment procedures were unnecessary for the GLC determination of cholesterol in foods.

\section{Experiment 3. Effect of derivatization for the GLC determination of cholesterol}

Since it is known that sterol acetates and the trimethylsilyl ether derivatives are useful for GLC analysis, effects of derivatization on the determination of cholesterol were investigated. Methyl esters of lard fatty acids were mixed with cholesterol to make a concentration of $0.1 \%$, and this was used for the

Table 5. Effect of pretreatment procedures on the assayed values of cholesterol.

\begin{tabular}{|c|c|c|c|c|c|c|c|}
\hline \multirow{2}{*}{ Sample oil } & \multirow{2}{*}{ Pretreatment } & \multicolumn{6}{|c|}{ Cholesterol (mg/100 g) } \\
\hline & & A. & B. & C. & D. & E. & Average \\
\hline \multirow{3}{*}{ Egg yolk lipids } & None & 1,460 & \multirow{3}{*}{1,510} & 1,385 & & \multirow[t]{3}{*}{1,480} & 1,441 \\
\hline & TLC & & & 1,106 & 1,520 & & 1,378 \\
\hline & Digitonide & & & 1,293 & & & 1,293 \\
\hline \multirow{3}{*}{ Oyster lipids } & None & 2,420 & \multirow{3}{*}{2,640} & 2,350 & & & 2,385 \\
\hline & TLC & 2,380 & & 2,208 & & & 2,409 \\
\hline & Digitonide & & & 2,176 & & & 2,176 \\
\hline
\end{tabular}

Table 6. Differences in cholesterol recoveries among several derivatives of cholesterol.

\begin{tabular}{clrccc}
\hline & \multicolumn{1}{c}{$\begin{array}{c}\text { Sterol } \\
\text { Serivative }\end{array}$} & \multicolumn{4}{c}{ Cholesterol (mg/100g) } \\
\cline { 3 - 6 } & & A. & B. & C. & E. \\
\hline $\begin{array}{c}\text { Lard fatty acid } \\
\text { methyl ester } \\
+\end{array}$ & $\begin{array}{l}\text { Free } \\
\text { Acetate } \\
\text { (TLC pretreatment) }\end{array}$ & 113 & 102 & 75 & 103 \\
$\begin{array}{c}\text { Cholesterol } \\
(100 \mathrm{mg} / 100 \mathrm{~g} \text { ester) }\end{array}$ & TMS & & & & \\
\hline
\end{tabular}


collaborative test. Table 6 shows the results from the four laboratories. When the recoveries were tested with the free form of cholesterol, good results showing $99 \%$ and $103 \%$ were obtained from two laboratories (Table 6). On the other hand, acetylation and trimethylsilation were also confirmed to be useful for the GLC determination of cholesterol.

The results from Experiments 2 and 3 showed that derivatization was unessential for the GLC determination of cholesterol in foods, because good separation of cholesterol from other impurities could be achieved without derivatization, and the recovery tests always gave good results. Therefore, it was concluded that the unsaponifiable matter of samples should be applied directly to GLC in order to save procedure time.

Experiment 4. Collaborative test for the determination of cholesterol in foods by the proposed method

Collaborative tests for the determination of cholesterol in several foods were performed by using the proposed method. A recovery test was first performed on a sample of lard with a known added amount of authentic cholesterol $(40.9 \mathrm{mg} / 100 \mathrm{~g}$ oil). As shown in Table 7, five laboratories obtained good results showing recoveries between 93 and 105\%, whereas one laboratory (B) received a high recovery value which should be excluded. The cholesterol contents of Kotama-gai (a type of clam) and Euphausia sp. were also determined by the proposed method. As shown in Table 7, deviation among the respective data obtained from the laboratories was small except for the datum on Kotama-gai from one laboratory (E). Table 8 shows the assayed values on the other samples carried out by two laboratories. The respective data were similar to each other. From these

Table 7. Collaborative tests for the determination of cholesterol in foods by the proposed method among six laboratories.

\begin{tabular}{lccccccc}
\hline \multirow{2}{*}{ Food } & \multicolumn{7}{c}{ Cholesterol (mg/100 g food) } \\
\cline { 2 - 8 } & A. & B. & C. & D. & E. & F. & Average \\
\hline Lard & 56.9 & 52 & 49 & 50.4 & 53.0 & 60 & 53 \\
$\begin{array}{l}\text { Lard + Cholesterol } \\
(40.9 \mathrm{mg} / 100 \text { g oil) }\end{array}$ & 95 & 99 & 92 & 89 & 95 & 99 & 94.8 \\
$\begin{array}{l}\text { Kotama-gai } \\
\text { (Gomphia melanaegis) }\end{array}$ & 3,030 & 2,872 & 2,690 & 2,977 & $(1,681)^{\mathrm{b}}$ & 2,855 & 2,884 \\
Euphausia sp. & 2,330 & 2,035 & 2,280 & 2,628 & 2,136 & 2,260 & 2,278 \\
\hline
\end{tabular}

${ }^{a}$ Recovery (\%) of added cholesterol is shown in parentheses. ${ }^{\mathrm{b}}$ Excluded from the calculation of the mean value. 
Table 8. Collaborative tests for the determination of cholesterol in foods by the proposed method between two laboratories.

\begin{tabular}{lcc}
\hline \multirow{2}{*}{ Sample food } & \multicolumn{3}{c}{ Cholesterol $(\mathrm{mg} / 100 \mathrm{~g}$ food) } \\
& A. & E. \\
\hline Shrimp (dried) & 462 & 469 \\
Adductor muscle (dried) & 123 & 124 \\
Salmon roe (salted) & 407 & 393 \\
\hline
\end{tabular}

collaborative studies we concluded that the proposed method was useful for the determination of cholesterol in foods as a simple and exact technique.

The authors wish to thank Sannosuke Tsuchiya, Science and Technology Agency, for his collaboration.

\section{REFERENCES}

1) Sperry, W. M., and Webb, M. (1950): A revision of the Schoenheimer-Sperry method for cholesterol determination. J. Biol. Chem., 187, 97-106.

2) Koga, Y. (1970): Studies on cholesterol in food (part 2). On animal food other than fish. Eiyo To Shokuryo (J. Jpn. Soc. Food Nutr.), 23, 269-275.

3) Idler, D. R., and Wiseman, P. (1972): Molluscan sterols: a review. J. Fish. Res. Board Can., 29, 385-398.

4) Teshima, S., and Kanazawa, A. (1972): Comparative study on the sterol composition of marine mollucks. Bull. Jpn. Soc. Sci. Fish., 38, 1299-1304.

5) Nakagawa, Y., Tsuji, K., Iwao, H., Tsuji, E., and Suzuki, S. (1979): Comparison of enzymatic, colorimetric and gas-chromatographic analyses in the assay of cholesterol. Eiyo To Shokuryo (J. Jpn. Soc. Food Nutr.), 32, 389-395.

6) Lisboa, B. P. (1976): Thin-layer chromatography of sterols and steroids, in Lipid Chromatographic Analysis, Vol. 2, ed. by Marinetti, G. V., Marcel Dekker, New York, pp. 339-478.

7) Carrol, K. K. (1961): Separation of lipid classes by chromatography on florisil. J. Lipid Res., 2, 135-141.

8) Matsumoto, T. (1958): Sterin, in Chemistry of Lipids, Vol. 1, ed. by Funahashi, S., Mori, S., Hara, I., Fukuba, H., and Matsumoto, T., Kyoritsu Shuppan, Tokyo, pp. 72-74 (in Japanese). 